\title{
Thermodynamic protonation constant values of meclizine and buclizine in acetonitrile-water binary mixtures
}

\author{
İkbal Demet NANE 1 (D), Ebru ÇUBUK DEMIRALAY $2 *$ (D) \\ 1 Department of Chemistry, Faculty of Science and Literature, Süleyman Demirel University, Isparta, Turkey. \\ 2 Department of Analytical Chemistry, Faculty of Pharmacy, Süleyman Demirel University, Isparta, Turkey. \\ * Corresponding Author. E-mail: ebrucubuk@sdu.edu.tr (E.C.); Tel. +90-246-211 0342.
}

Received: 03 October 2020 / Revised: 24 November 2020 / Accepted: 08 December 2020

\begin{abstract}
In the study, the retention times ( $\left.t_{R}\right)$ values for meclizine (MCZ) and buclizine (BCZ) structurally related benzhydrylpiperazine were determined to modeling the dependence of retention on the acetonitrile concentration in the mobile phase. Reversed-phase liquid chromatography (RPLC) analysis of the MCZ and BCZ was realized with polar embedded amide $(15 \times 0.46 \mathrm{~cm}$ I.D, $5 \mu \mathrm{m})$ column. The mobile phase $\mathrm{pH}$ range is selected from 5.0-9.0 to determine the structural changes due to protonation that result from a change in $\mathrm{pH}$. The different retention time were attributed to their different hydrophobicities and ionization degree. The thermodynamic protonation constant $\left({ }_{S}^{S} p K_{a}\right)$ value for investigated compounds was calculated using the $t_{\mathrm{R}}$ relationship to $\mathrm{pH}$ of the mobile phase and effect of the activity coefficients. Linear correlation between ${ }_{S}^{S} p K_{a}$ values and macroscopic parameters $\left(\mathrm{X}_{A C N}, 1 / \varepsilon\right)$ was also determined.
\end{abstract}

KEYWORDS: Benzhydrylpiperazine compounds; thermodynamic value; extrapolation methods; reversed-phase liquid chromatography.

\section{INTRODUCTION}

$\mathrm{H}_{1}$ antihistamines are used widely in the treatment of allergic disorders. These medications are most effective in relieving the symptoms of seasonal rhinitis and conjunctivitis. Some first-generation $\mathrm{H}_{1}$ antagonists (e.g., dimenhydrinate, cyclizine, meclizine, buclizine, and promethazine) have been widely used to prevent motion sickness. Antiemetic effects of these $\mathrm{H}_{1}$ antihistamines can be beneficial in treating vertigo or postoperative emesis [1].

The structure and biological behavior of meclizine (MCZ) are similar to buclizine (BCZ). These compounds are a piperazine-derivative antihistamine. Members of the piperazine class of agents are structurally related to both the ethylenediamine and the benzhydryl ethers of ethanolamines. Their structures include the 2-carbon separation between nitrogen atoms, which is incorporated into the piperazine ring. Diarylmethylene groups (benzhydryl substituents) are attached to one of the nitrogen atoms, and an alkyl substituent is attached to the other nitrogen [2].

The chromatographic retention behavior of compounds in the reversed-phase liquid chromatography (RPLC) method depends on the interaction between the mobile phase and the stationary phase [3]. RPLC column selection is an important part of developing an analytical method. Traditionally, C18 columns are preferred for analysis of apolar compounds in method optimization studies. Where these compounds are difficult or impossible to elute from the column, different packing materials are preferred. Columns play an active role in retention. Besides, in the chromatographic analysis of the compounds, the correct selection of the concentration of the organic modifier in the mobile phase and $\mathrm{pH}$ value is very important. Different approaches are used to estimate the retention time of the compound with the correct choice of mobile phase [3-6].

If the protonation constant $\left(\mathrm{p} K_{\mathrm{a}}\right)$ value of the basic analyte to be determined at different organic modifier concentrations is known, the retention time $\left(t_{R}\right)$ in RPLC can be easily estimated using thelinear solvation relationships (LSERs) method [7-9]. 
According to this approach, the $t_{R}$ value of basic compounds can be calculated using the Eq. $(1)[8,9]$

$$
t_{R}=\frac{t_{R H A}+t_{R A} 10^{ \pm}\left(p H-p K_{a}\right)}{1+10^{ \pm\left(p H-p K_{a}\right)}}
$$

The $t_{R H A}$ and the $t_{R A}$ are expressed as the retention time of ionized and non-ionized forms, respectively. A negative sign is used to calculate basic compounds [8,9]. Eq. (2) can be derived from Eq. (1) as follows:

$$
t_{R}=t_{R H A}\left[\frac{1+\left(\frac{t_{R A}}{t_{R H A}}\right) 10^{ \pm(p H-p K a)}}{1+10^{ \pm(p H-p K a)}}\right]
$$

If in Eq. (2) the logarithm of the equation is taken:

$$
\begin{aligned}
& \log \left(t_{R}\right)=\log \left\{t_{R H A}\left[\frac{1+\left(\frac{t_{R A}}{t_{R H A}}\right) 10^{ \pm\left(p H-p K_{a}\right)}}{1+10^{ \pm(p H-p K a)}}\right]\right\} \\
& \log \left(t_{R}\right)=\log \left(t_{R H A}\right)+\log \left(\frac{1+f 10^{ \pm(p H-p K a)}}{1+10^{ \pm\left(p H-p K_{a}\right)}}\right)
\end{aligned}
$$

The $f$ in the equation is the ratio of $t_{R}$ values $\left(t_{R A} / t_{R H A}\right)$. The equation in parenthesis is a hyperbolic function. The logarithm of this function is the sigmoidal function and this equation can be expressed as $[8,9]$ :

$$
\log \left(\frac{1+f 10^{ \pm\left(p H-p K_{a}\right)}}{1+10^{ \pm\left(p H-p K_{a}\right)}}\right)=\frac{U}{1+V 10^{ \pm\left(p H-p K_{a}\right)}}
$$

$\mathrm{U}$ and $\mathrm{V}$ are two fitting coefficients. The initial estimates for $\mathrm{U}$ and $\mathrm{V}$ were set -1 and 4 , respectively $[8,9]$. .Using Eq. (5)generated by this LSER approach, the $\log \left(t_{R}\right)$ value of the analyte can be calculated. Residual values for compounds were calculated as the difference between the estimated and measured $\log \left(\mathrm{t}_{\mathrm{R}}\right)$. Then these values were squared and summed. The best fits were obtained by minimizing the sum of squares of residuals (SSR). Microsoft Excel SOLVER was then started with the default regression [8,9].

Many drug compounds include at least one acidic and/or basic functionality, and the dissociation state of these compounds play a large role in determining the physicochemical properties (lipophilicity, solubility, protonation constant) of a compound. Protonation constant value $\left(\mathrm{p} K_{\mathrm{a}}\right)$ is a physicochemical parameter that allows the estimation of ionization of basic compounds at different $\mathrm{pH}$ conditions. Information on $\mathrm{p} K_{\mathrm{a}}$ value plays the main role in the expansion of drug delivery formulations [9]. This physicochemical parameter affects the ADME (absorption, distribution, metabolism, and excretion) properties of the active pharmaceutical ingredients (APIs) [10-12]. On the other hand, intestinal drug absorption is a key step for oral availability and systemic exposure of drug candidates.

For ionizable compounds insoluble in water, the determination of $\mathrm{p} K_{\mathrm{a}}$ is difficult. Because of this, organic or hydro-organic solvent mixtures are needed for ${ }_{S}^{S} p K_{a}$ determination [2,9]. In recent years, studies showing solvent-solvent and solute-solvent interaction in organic modifier-water mixtures in the liquid chromatographic analysis have attracted considerable attention $[13,14]$.

Acetonitrile (ACN)-water mixtures are widely used in RPLC and other analytical methods to affect the solubility, absorption property, and chromatographic behavior of the compound [15-17]. One of the welldefined separation methods to estimate $\mathrm{p} K_{\mathrm{a}}$ values is the RPLC method. It is a method based on differences in the retention of protonated and unprotonated compounds [18].

By this method, the $t_{R}$ values are determined at $\mathrm{pH}$ values of the mobile phase in $\mathrm{p} K_{\mathrm{a}}$ determination [19]. Furthermore, the organic solvent added to the mobile phase has a great effect on retention. $t_{R}$ values were measured at each $\mathrm{pH}$ of the mobile phase, depending on the percentage of aprotic ACN selected in this study. ${ }_{S}^{S} p K_{a}$ values of MCZ and BCZ in hydro-organic mixtures were also calculated by using this nonlinear relationship [20].

Although $\mathrm{p} K_{\mathrm{a}}$ values of $\mathrm{MCZ}$ and $\mathrm{BCZ}$ with software packages based on the molecular structure can be found in the literature [21,22], the dissociation behavior of compounds in $\mathrm{ACN}$-water hydro-organic mixture 
was still unknown. There is only one study in the literature regarding the $p K_{a}$ value of MCZ [23]. There is no study done with the RPLC method. Therefore the RPLC method was chosen to determine the ${ }_{s}^{S} p K_{a}$ values of the benzhydrylpiperazine antihistamine compounds with high precision and accuracy [18, 24-26]. The study aimed was to determine the influence of ACN content on retention times in the microheterogeneity region. The $t_{R}$ values of $\mathrm{BCZ}$ and MCZ in varying $\mathrm{ACN}$ content and the $\mathrm{pH}$ range of 5.0-9.0 were measured. The ${ }_{s}^{s} p K_{a}$ values for these benzhydrylpiperazine antihistamines were determined using the $\mathrm{pH}-\mathrm{t}_{\mathrm{R}}$ relationship. Aqueous $\mathrm{p} K_{\mathrm{a}}\left({ }_{w}^{w} p K_{a}\right)$ values for $\mathrm{MCZ}$ and $\mathrm{BCZ}$ were calculated using the mole fraction and dielectric constant of $\mathrm{ACN}$ [27].

\section{RESULTS}

\subsection{Determination of $t_{R}$ values for antihistamines}

Octadecyl stationary phases (C18) are most commonly used in the analysis of these compounds by the RPLC method, but an investigation of chromatographic behavior of MCZ and BCZ by an amide-based column has not been reported so far. C18 columns were preferred for liquid chromatographic analyzes of MCZ and BCZ. Peak shapes and very good repeatability results were obtained in the analysis performed with this chosen Ascentis RP-Amide $(15 \times 0.46 \mathrm{~cm}$ I.D, $5 \mu \mathrm{m})$ column. Acetonitrile, which is a polar aprotic solvent, readily soluble in water and preferred for the analysis of nonpolar compounds in RPLC analysis, was used as an organic modifier.

In this work, the $t_{R}$ values of $\mathrm{MCZ}$ and $\mathrm{BCZ}$ were determined using the simultaneous action of $\mathrm{ACN}$ and $\mathrm{pH}$ in the mobile phase. The logt $\mathrm{t}_{\mathrm{R}}$ values of the compounds were estimated using Eq. (5). The differences between the experimental and predicted $\log t_{R}$ values were taken and the differences were squared. The results were obtained by minimizing the sum of squares of residuals (SSR) value. For ACN- water binary mixture containing $65 \%(\mathrm{v} / \mathrm{v}) \mathrm{ACN}$, the logt $\mathrm{R}_{\mathrm{R}}$ values calculated with the LSER approach are given in Table 1. SOLVER program was then started with the default regression. This procedure was repeated for the $t_{R}$ values at the $\mathrm{pH}$ of the mobile phase and studied ACN concentration.

The differences between the experimental and predicted $t_{R}$ values calculated according to this approach are quite small. When $t_{R}$ values calculated by the LSER approach are plotted against experimental $t_{R}$ values, $a$ linear function is obtained (the correlation coefficient is at least 0.99). A regression between predicted and experimental $t_{R}$ values should be a slope of 1.00 and an intercept of 0.0 . In this study, the regression slope and intercept values were approximately close to 1 and 0 , respectively (Figure 1).

\subsection{Determination of $\mathrm{p} K_{\mathrm{a}}$ values}

Experimental $t_{R}$ values of the $\mathrm{MCZ}$ and $\mathrm{BCZ}$ were determined at the $\mathrm{pH}$ of the mobile phase and composition. The change of $t_{R}$ value in mobile phase $\mathrm{pH}$ in ACN-water binary mixture containing $62 \% \mathrm{ACN}$ $(\mathrm{v} / \mathrm{v})$ is given in Figure $2[28,29]$. It is given in the blank sample at each $\mathrm{pH}$ value in the chromatogram. Low aqueous solubility is a major problem in drug development. $\mathrm{MCZ}$ and $\mathrm{BCZ}$ are sparingly soluble in water

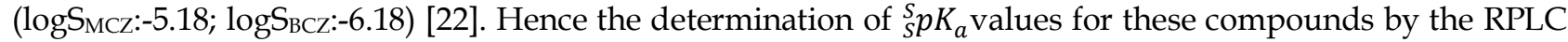
method was performed in the ACN-water binary mixtures.
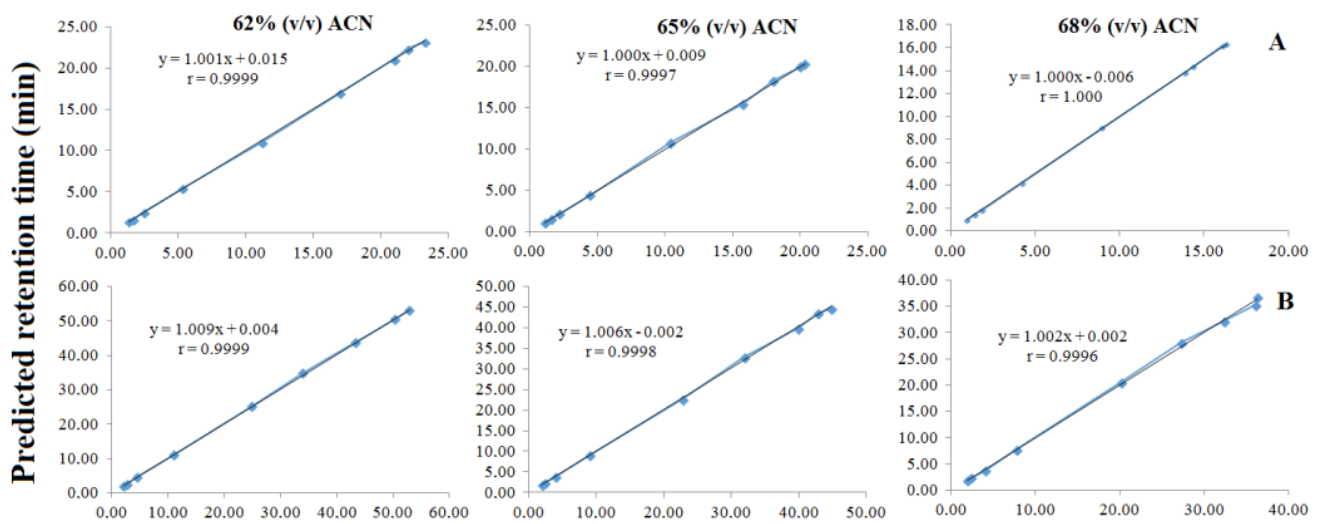

Measured retention time $(\mathrm{min})$

Figure 1. Predicted vs. measured retention times for $\mathrm{A}) \mathrm{MCZ}$ and $\mathrm{B}) \mathrm{BCZ}$. 
Table 1. Predicted $t_{R}$ values by LSER approach for MCZ and BCZ

\begin{tabular}{|c|c|c|c|c|c|c|c|}
\hline & $\mathrm{pH}$ & $\begin{array}{c}t_{R} \\
\text { (experimental) }\end{array}$ & $\begin{array}{c}t_{R} \\
\text { (predicted) }\end{array}$ & \multirow{10}{*}{$\begin{array}{c}U=0.143 \\
V=2.876 \\
f=29.263\end{array}$} & $\log t_{R}(\exp )$. & $\log _{R}($ pre.) & $\begin{array}{l}\left(\log t_{\text {Rexp }}\right. \\
\left.\log t_{\text {Rpre }}\right)^{2}\end{array}$ \\
\hline \multirow{9}{*}{ MCZ } & 5.0 & 1.088 & 1.100 & & 0.037 & 0.041 & $2.27 .10^{-05}$ \\
\hline & 5.5 & 1.553 & 1.522 & & 0.191 & 0.182 & $7.55 .10^{-05}$ \\
\hline & 6.0 & 2.212 & 2.147 & & 0.345 & 0.332 & $1.69 .10^{-04}$ \\
\hline & 6.5 & 4.454 & 4.422 & & 0.649 & 0.646 & $9.60 .10^{-06}$ \\
\hline & 7.0 & 10.406 & 10.780 & & 1.017 & 1.033 & $2.36 .10^{-04}$ \\
\hline & 7.5 & 15.791 & 15.473 & & 1.198 & 1.190 & 7.82.10-05 \\
\hline & 8.0 & 18.005 & 18.280 & & 1.255 & 1.262 & $4.33 .10-05$ \\
\hline & 8.5 & 20.033 & 20.007 & & 1.302 & 1.301 & $3.18 .10-07$ \\
\hline & 9.0 & 20.355 & 20.267 & & 1.309 & 1.307 & $3.54 .10^{-06}$ \\
\hline \multirow{11}{*}{ BCZ } & & & & \multirow{11}{*}{$\begin{array}{c}U=0.554 \\
V=3.011 \\
f=46.102\end{array}$} & & SSR* & $6.38 .10^{-04}$ \\
\hline & 5.0 & 1.909 & 1.932 & & 0.281 & 0.286 & $2.78 .10^{-05}$ \\
\hline & 5.5 & 2.418 & 2.400 & & 0.383 & 0.380 & $1.07 .10^{-05}$ \\
\hline & 6.0 & 4.015 & 3.900 & & 0.604 & 0.591 & $1.60 .10^{-04}$ \\
\hline & 6.5 & 9.032 & 9.133 & & 0.956 & 0.961 & $2.35 .10^{-05}$ \\
\hline & 7.0 & 22.723 & 22.650 & & 1.356 & 1.355 & $1.93 .10^{-06}$ \\
\hline & 7.5 & 31.879 & 32.803 & & 1.504 & 1.516 & $1.54 .10^{-04}$ \\
\hline & 8.0 & 39.880 & 39.732 & & 1.601 & 1.599 & $2.61 .10^{-06}$ \\
\hline & 8.5 & 42.867 & 43.571 & & 1.632 & 1.639 & $5.00 .10^{-05}$ \\
\hline & 9.0 & 44.810 & 44.521 & & 1.651 & 1.649 & $7.90 .10^{-06}$ \\
\hline & & & & & & SSR & $4.39 .10^{-04}$ \\
\hline
\end{tabular}

*SSR: Sum of squares of residuals

The ${ }_{S}^{S} p K_{a}$ values at studied ACN percentages were obtained by fitting the $\mathrm{t}_{\mathrm{R}} \mathrm{pH}$ data, usually bynonlinear regression. ${ }_{s}^{S} p K_{a}$ values depend on the ACN composition [30] and the ${ }_{s}^{S} p K_{a}$ values of MCZ and $B C Z$ were determined from the combined effect of $\mathrm{pH}$ of the mobile phase and experimental $t_{\mathrm{R}}$ values. The sigmoidal behavior was observed when the $t_{R}$ values of MCZ and BCZ measured in the $\mathrm{pH}$ 5.0-9.0 range were plotted (Figure 3). ${ }_{S}^{S} p K_{a}$ values of the compounds were calculated by nonlinear regression (NLREG) program using $\mathrm{pH}-\mathrm{t}_{\mathrm{R}}$ data. The thermodynamic ${ }_{S}^{S} p K_{a}$ values and intrinsic $\mathrm{t}_{\mathrm{R}}$ values of $\mathrm{MCZ}$ and BCZ in different ACN concentrations were calculated by using nonlinear squares data. Table 2 list the calculated data by the NLREG program [31], together with the standard deviations. The ${ }_{s}^{S} p K_{a}$ values were also calculated by the SOLVER program (Table 2). The results obtained by these two approaches are compared in Table 2.

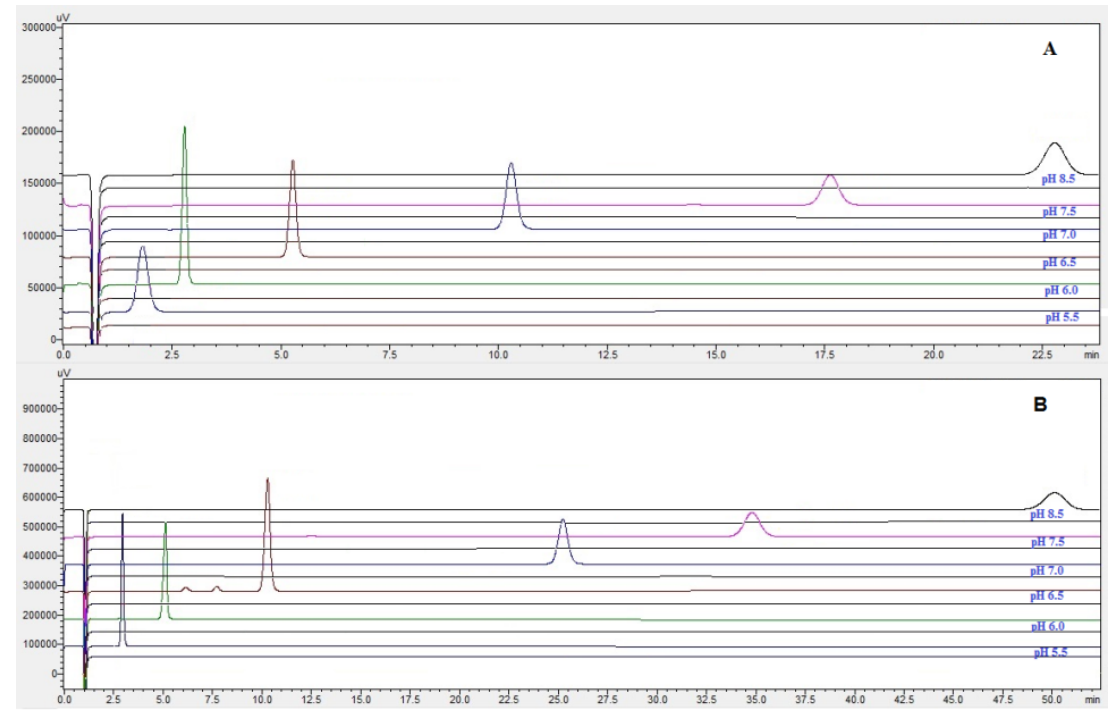

Figure 2. Overlaid chromatograms obtained from studied compounds for a mobile phase composed of ACN-water 462 binary mixture (62:38, v/v\%) at different mobile phase $\mathrm{pH}$. A)MCZ and B)BCZ. 


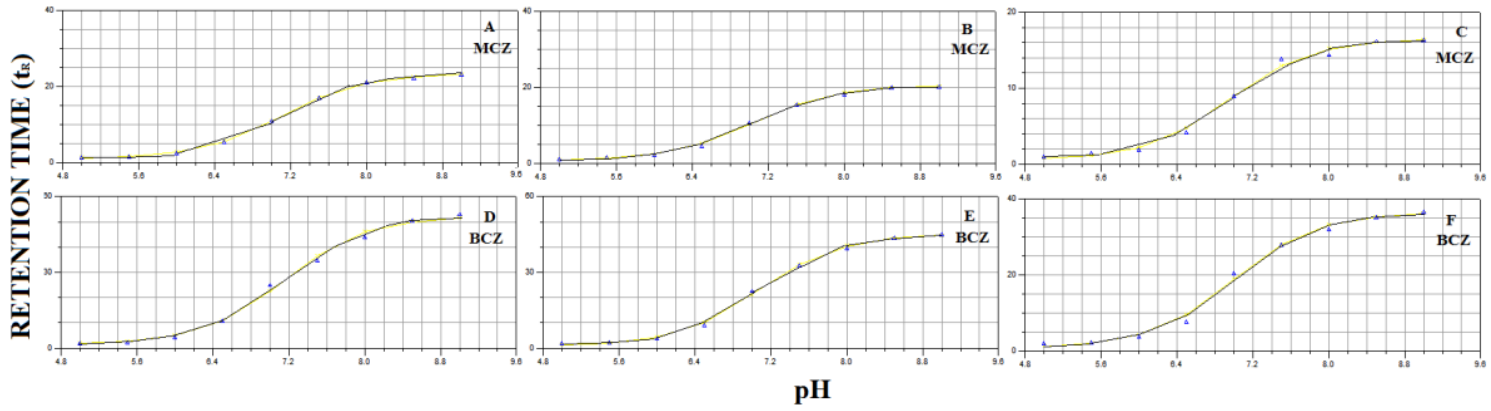

Figure 3. The retention time of the studied compounds is plotted against as a function of mobile phase $\mathrm{pH}$ using the NLREG program. A-D) ACN-water mixture containing $62 \%(v / v) A C N$; B-E) ACN-water mixture containing $65 \%(\mathrm{v} / \mathrm{v}) 479 \mathrm{ACN}$; C-F) ACN-water mixture containing $68 \%$ (v/v) ACN.

Table 2. NLREG and SOLVER program data for studied compounds.

\begin{tabular}{cccccc}
\hline Compounds & $\begin{array}{c}\text { ACN } \\
(\mathbf{v} / \mathbf{v}) \%\end{array}$ & $t_{R B H^{+}}$ & NLREG & & SOLVER \\
& $\mathbf{6 0}$ & $2.371(0.147)^{*}$ & $60.626(1.586)$ & $7.200(0.066)$ & 7.185 \\
& $\mathbf{6 2}$ & $1.661(0.038)$ & $52.159(1.172)$ & $7.149(0.057)$ & 7.127 \\
\multirow{6}{*}{ BCZ } & $\mathbf{6 5}$ & $0.977(0.057)$ & $45.042(0.609)$ & $7.069(0.035)$ & 7.036 \\
& $\mathbf{6 8}$ & $0.869(0.038)$ & $36.407(0.787)$ & $6.992(0.058)$ & 6.931 \\
& $\mathbf{6 0}$ & $1.289(0.098)$ & $28.119(0.224)$ & $7.152(0.021)$ & 7.131 \\
& $\mathbf{6 2}$ & $1.067(0.092)$ & $23.410(0.100)$ & $7.102(0.011)$ & 7.086 \\
$\mathbf{M C Z}$ & $\mathbf{6 5}$ & $0.701(0.028)$ & $20.513(0.296)$ & $7.037(0.039)$ & 7.005 \\
& $\mathbf{6 8}$ & $0.622(0.015)$ & $16.483(0.365)$ & $6.957(0.061)$ & 6.914 \\
\hline
\end{tabular}

*Standard deviation value

These two programs gave concordant results. The ${ }_{s}^{S} p K_{a}$ values were found to decrease slightly with the increasing percentage of ACN in the mobile phase. The data given in Table 2 are consistent with the $\mathrm{p} K_{\mathrm{a}}$ values of the piperazine ring [32-34].

As can be seen, the chromatographic retention of studied compounds with a benzhydrylpiperazine substituent increases strongly in the $\mathrm{pH}$ range 5.0-9.0. The sigmoidal curves were shown as continuous lines and the plotted points (Figure 3). Both compounds were an ionized form $\left(\mathrm{BH}^{+}\right)$at $\mathrm{pH}$ 5.0. Protonation of the base causes peak tailing in C18, C8 columns [28,29]. In the study with different C18 columns (XBridge, Kinetex $\mathrm{C} 18$, Gemini NX, etc.) at $\mathrm{pH} 5.0, \mathrm{MCZ}$ and $\mathrm{BCZ}$ were shown very long interaction with these columns and shown high retention times. The retention time of the amide column selected for this study is very low compared to the retention times of other C18 columns. The results also clearly indicate that benzhydrylpiperazine antihistamines with piperazine substituents behave quite differently from those with a substituent on the side chain.

As shown in Table 2, these two compounds have one ${ }_{s}^{S} p K_{a}$ value corresponding to the basic functionalgroup. ${ }_{s}^{S} p K_{a}$ value of the piperazine nitrogen linked to the methyl chain was influenced by the nature and the position of the substituent on the phenylmethyl attached to the 1-(4-chlorobenzylhydryl)piperazine. The dissociation equilibriums are given in Figure 4.

System suitability tests are an integral part of HPLC method development. The US Pharmacopoeia (24th) suggests that system suitability tests can be performed prior to analysis. For this test, combined effect of organic modifier content and ${ }_{S}^{S} p H$ of the mobile phase on the retention behavior of MCZ and BCZ was determined. The optimum separation condition of $\mathrm{MCZ}$ and $\mathrm{BCZ}$ was determined as ACN-water mixture containing $62 \% \mathrm{ACN}(\mathrm{v} / \mathrm{v})$ and $\mathrm{pH} 5.5$. The parameters include capacity factor, theoretical plate number, retention time, tailing factor, selectivity, and RSD\% of peak height or area for repetitive injections. The tailing factor and capacity factors were obtained as 1.17 and 1.22 for MCZ, 1.20 and 2.96 for BCZ, respectively. The theoretical plate numbers (N) were 3928 for MCZ, 4227 for BCZ. The selectivity factor was 2.43. The variation in retention time and peak area for five replicate injections of all compounds reference solutions gave RSDs of $0.06 \%$ and $0.32 \%$ for $\mathrm{MCZ}, 0.01 \%$ and $0.18 \%$ for $\mathrm{BCZ}$, respectively. The results obtained from system suitability tests are inagreement with the USP requirements. 


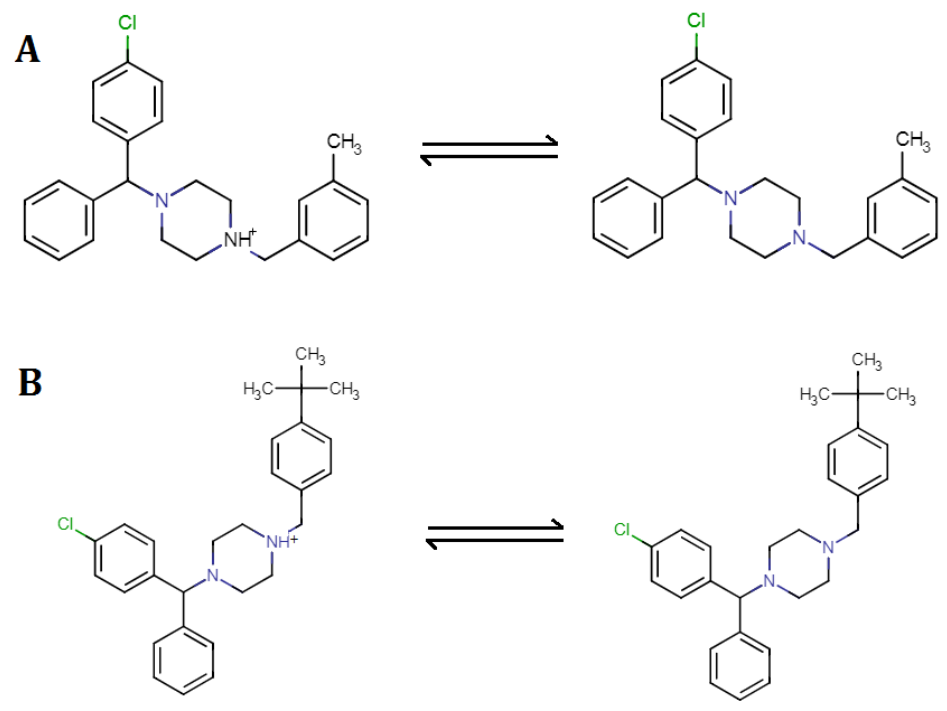

Figure 4. Protonation equilibriums of A) $\mathrm{MCZ}$ and B) BCZ.

\section{DISCUSSION}

$\mathrm{MCZ}$ and $\mathrm{BCZ}$ show one dissociation equilibrium corresponding to the deprotonation of $\mathrm{N}-4$ the piperazine nitrogen linked to the methyl chain. On the $A C N$-rich side $\left(0.15 \leq X_{A C N} \leq 0.75\right)$, preferential solvation by water exists, which could explain the low decrease of ${ }_{s}^{S} p K_{a}$ values of $\mathrm{MCZ}$ and BCZ when the percentage of acetonitrile increases [35]. $\mathrm{p} K_{\mathrm{a}}$ value is generally determined under standard conditions $\left(25^{\circ} \mathrm{C}\right.$, constant ionic strength). MCZ and BCZ were determined at $37{ }^{\circ} \mathrm{C}$ with this study. The $\mathrm{p} K_{\mathrm{a}}$ value should be determined at bio relevant temperature $(37 \mathrm{\circ})$ to determine the absorption and distribution of the properties of the drug.

Since these hydrophobic antihistamines are not soluble in a water, ${ }_{s}^{S} p K_{a}$ values in the water medium cannot be determined by the RPLC method. For this, aqueous ${ }_{w}^{w} p K_{a}$ values were calculated by using the mole fraction $\left(\mathrm{X}_{A C N}\right)$ and dielectric constant $(\varepsilon)$ values of acetonitrile determined by Barbosa et al.[27] in the ACN concentrations studied. In the present study, macroscopic parameters (dielectric constant and mole fraction) were used to calculate the ${ }_{w}^{w} p K_{a}$ values of hydrophobic compounds in water. Considering the NLREG data depicted in Table 2, the ${ }_{S}^{S} p K_{a}$ value of $\mathrm{MCZ}$ and $\mathrm{BCZ}$ were plotted against the reciprocal of the dielectric constant $(1 / \varepsilon)$, and the $X_{A C N}$ (Figure 5). The data are shown as average value of three repetitive analyses with error bars as the standard deviations. The correlations between ${ }_{s}^{S} p K_{a}$ values with the $1 / \varepsilon$ and $\mathrm{X}_{A C N}$ of the studied binary mixtures are linear with correlation coefficients greater than 0.99 (Figure 5). The intercept value of the linear equation in the $\mathrm{X}_{A C N}{ }_{s}^{S} p K_{a}$ relationship gave the ${ }_{w}^{w} p K_{a}$ value. In the linear equation in the $1 / \varepsilon-$ ${ }_{S}^{S} p K_{a}$ relationship, $\varepsilon=78.51$ is taken. Using this value, ${ }_{w}^{w} p K_{a}$ value was calculated. ${ }_{w}^{w} p K_{a}$ values calculated using these linear equations were given in Table 3 . The basic protonation site has a negative slope as expected for the basic group. ${ }_{w}^{w} p K_{a}$ values calculated from these two approaches were compatible with each other.

Data on ${ }_{s}^{S} p K_{a}$ values in ACN-water binary mixtures are scarce and only the $\mathrm{p} K_{\mathrm{a}}$ value of $\mathrm{MCZ}$ was found in the literature [23]. This value was determined in chloroform and the method used was different [23]. In this work, the calculated ${ }_{w}^{w} p K_{a}$ value for compounds is consistent with the values calculated from the Chemicalize program ( $\mathrm{pK}$ a: 7.71 for $\mathrm{BCZ} ; \mathrm{p} K_{\mathrm{a}}: 7.60$ for $\mathrm{MCZ}$ ) [22].Since $\mathrm{MCZ}$ and $\mathrm{BCZ}$ are structurally analogous, there are limited studies in the literature regarding the simultaneous chromatographic separation of these compounds. Arayne and co-workers [36] were reported that separation of MCZ and BCZ simultaneously was carried out in $\mathrm{C} 18$ column. Separation was carried out in $\mathrm{ACN}-$ water $(80: 20, \mathrm{v} / \mathrm{v})$ and $\mathrm{pH} 2.6$ at room temperature. In this study, experiments have been made by changing the mobile phase composition, $\mathrm{pH}$ and flow rate, and the optimum separation condition has been found. As a further example, Sher and co-workers [37] were reported that simultaneous separation of MCZ and BCZ was carried out in C18 column at $25^{\circ} \mathrm{C}$. In the mobile phase, $\mathrm{ACN}$ was used as an organic modifier and heptane sulfonic acid was used as an ion pair former. No optimization study has been found in this study. There is no method optimization study for these trial and error method. In this study, both the $\mathrm{p} K_{\mathrm{a}}$ values of the compounds and the optimum separation conditions of the compounds were determined by using the $\mathrm{pH}-\mathrm{t}_{\mathrm{R}}$ and $\mathrm{pH}-\mathrm{k}$ relationship. In addition, in this study, chromatographic separation was carried out on an amide column. Determinations made with this column is the first study in the literature. 

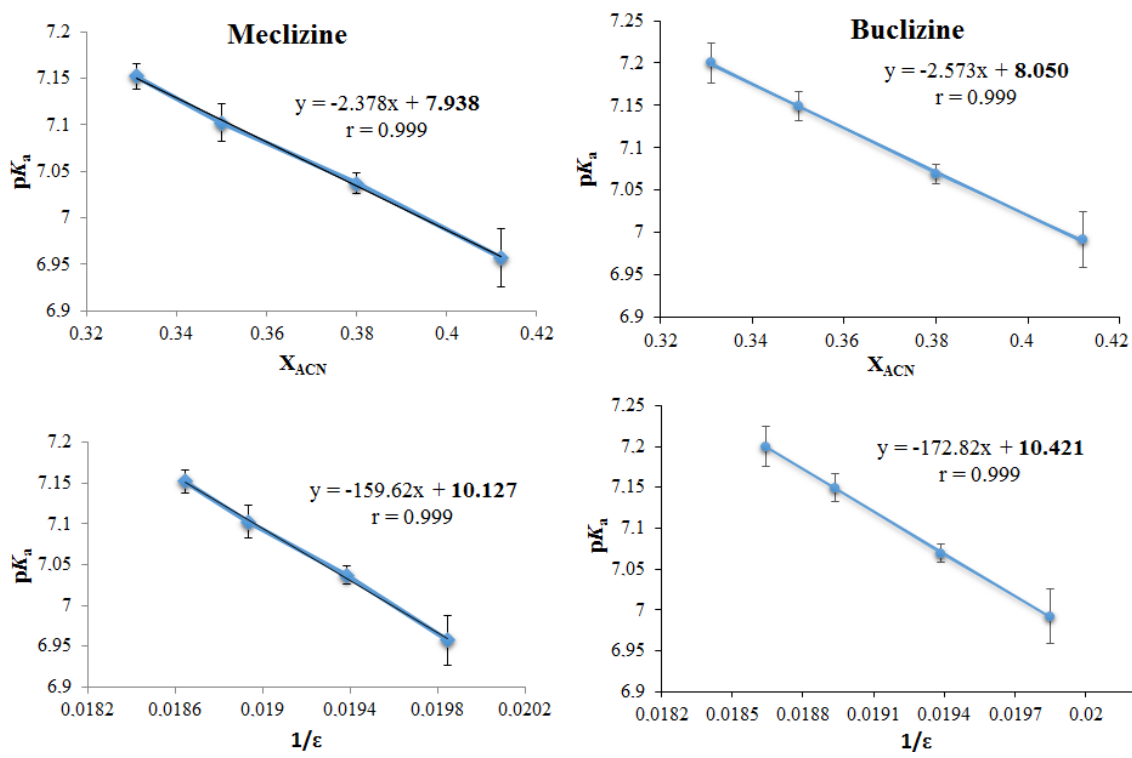

Figure 5. Linear relationships between ${ }_{S}^{S} p K_{a}$ values and macroscopic parameters.

Table 3. Calculated aqueous $\mathrm{p} K_{\mathrm{a}}$ values for $\mathrm{MCZ}$ and $\mathrm{BCZ}$.

\begin{tabular}{ccc}
\hline \multirow{2}{*}{ Compounds } & \multicolumn{2}{c}{${ }^{w} p K_{\boldsymbol{a}}$} \\
\hline $\mathrm{MCZ}$ & 8.090 & $\boldsymbol{X}_{A C N^{-}}{ }_{\boldsymbol{s}}^{\boldsymbol{s}} \boldsymbol{p} \boldsymbol{p} \boldsymbol{K}_{\boldsymbol{a}}$ \\
\hline $\mathrm{BCZ}$ & 8.216 & 7.938 \\
\end{tabular}

The extent of ionization of a drug has an important effect on its ADME properties. Understanding how changes in $\mathrm{pH}$ alter the ionization of drugs is very important since unionized drugs cross membranes. Percentages of ionization for the studied drugs in ionized and non-ionized forms at certain $\mathrm{pH}$ values were calculated by Henderson-Hasselbach equation [38]. These values were calculated using ${ }_{w}^{w} p K_{a}$ values calculated for basic compounds. Graphs showing the \% ionization values in $\mathrm{pH}$ range 1.0-11.0 are given in Figure 6. Compounds containing basic functional groups are exactly $50 \%$ ionized at their $\mathrm{p} K_{\mathrm{a}}$ values. It is known that the basic compounds $\mathrm{p} K_{\mathrm{a}}$ value is above 2 units completely in non-ionized form.
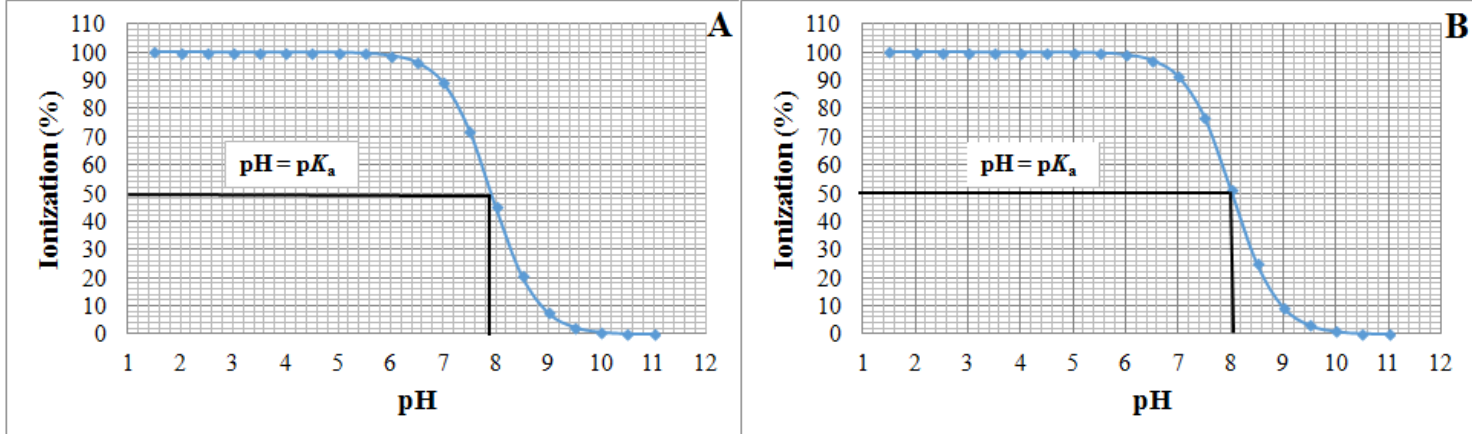

Figure 6. Percentage ionization of $\mathrm{A}) \mathrm{MCZ}$ and $\mathrm{B}) \mathrm{BCZ}$ as a function of $\mathrm{pH}$.

\section{CONCLUSION}

In this study, the first data for which retention times are estimated by using the LSER approach for MCZ and BCZ and ${ }_{S}^{S} p K_{a}$ values are calculated with SOLVER and NLREG programs are presented. The $\mathrm{pH}$ value $\left.{ }_{s}^{S} p H\right)$ in the ACN-water binary mixture was used as the mobile phase was used instead of the $\mathrm{pH}\left({ }_{w}^{w} p H\right)$ value in the water. For this, an RPLC assay was performed at four different concentrations of ACN and the ${ }_{s}^{S} p K_{a}$ values of the compounds were calculated by using the relationships between retention times and eluent $\mathrm{pH}$. Experimental studies were carried out using a special amide column to obtain appropriate interaction between 
analyte and column. This is the first study to describe the chromatographic behavior of MCZ and BCZ in ACNwater mixtures at $37^{\circ} \mathrm{C}$. The retention values of the compounds depending on the mobile phase $\mathrm{pH}$ can be used for method optimization in chromatographic analysis of MCZ and BCZ. Percent ionization of the studied compounds in body fluids and their regions was estimated by this study.

\section{EXPERIMENTAL}

\subsection{Chemicals}

None of the chemicals used in this study were purified. $\mathrm{MCZ}$ and $\mathrm{BCZ}$ were sourced from SigmaAldrich (St. Louis, USA). Acetonitrile $(\mathrm{ACN})$, sodium hydroxide $(\mathrm{NaOH})$, o-phosphoric acid $\left(\mathrm{o}-\mathrm{H}_{3} \mathrm{PO}_{4}\right)$, potassium hydrogen phthalate (KHP) were purchased from Merck (Darmstadt, Germany).

\subsection{Apparatus}

A chromatographic determination was carried out by an HPLC system (Shimadzu Technologies, Kyoto, JAPAN). HPLC system consists of a UV-Vis detector (SPD-20A), a column oven (CTO-20A), a pump (LC20AD), a degasser (DGU-20A3), and an injection system. Absorbance measurements were made with a UV detector at $230 \mathrm{~nm}$. The polar embedded Ascentis RP-Amide $\left(15 \times 0.46 \mathrm{~cm}\right.$ I.D, $5 \mu \mathrm{m}$, Sigma-Aldrich $\left.{ }^{\circledR}\right)$ column was chosen for the chromatographic determination of the compounds. $\mathrm{pH}$ measurements were performed with a $\mathrm{pH}$ meter (Mettler Toledo, Schwerzenbach, Switzerland). In electrode calibration, KHP solution (0.05 $\mathrm{mol} / \mathrm{kg}$ ) was prepared in ACN-water binary mixture [40]. Ultra pure water was supplied from a Direct-Q ${ }^{\circledR 3}$ UV water purification system (Millipore, Bedford, MA, USA).

\subsection{Chromatographic study}

Determination of $t_{\mathrm{R}}$ values of MCZ and $\mathrm{BCZ}$ was carried out in ACN-water hydro organic mixtures containing $60 \%, 62 \%, 65 \%$, and $68 \%(\mathrm{v} / \mathrm{v}) \mathrm{ACN}$ at $\mathrm{pH} 5.0-9.0 .0-\mathrm{H}_{3} \mathrm{PO}_{4}$ was added as the buffer component in the mobile phase. $30 \mathrm{mM}$ was kept constant in all mobile phases. In the mobile phases prepared at these high ACN concentrations, the buffer in the medium did not precipitate. The studied mobile phase $\mathrm{pH}$ value was adjusted with $1 \mathrm{M} \mathrm{NaOH}$.

Solutions of standard compounds were injected into the HPLC system at a constant flow rate (2 $\mathrm{mL} / \mathrm{min}$ ). The samples were injected into the HPLC column in a volume of $20 \mu \mathrm{L}$. The relative standard deviation (RSD\%) of measured $t_{R}$ values is less than $1.0 \%(n=3)$. The chromatographic study was performed at $37{ }^{\circ} \mathrm{C}$.

\subsection{Preparation of standard solutions}

When MCZ and BCZ have less solubility ( $\log S:-5.18$ for MCZ and $\log S:-6.18$ for BCZ) [22] in water, they are prepared by dissolving in $\mathrm{ACN}$-water hydro organic mixtures. The solutions were stored at a constant concentration $(100 \mu \mathrm{g} / \mathrm{mL})$ and at $4{ }^{\circ} \mathrm{C}$, away from sunlight. Capacity factors $(\mathrm{k})$ for each compound and mobile phase were calculated using the expression $k=\left(t_{R}-t_{0}\right) / t_{0}$. The dead time $\left(t_{0}\right)$ was measured by injecting uracil solution (Sigma, USA, $0.1 \%$, in water), which was established for each mobile phase composition and $\mathrm{pH}$ studied.

\subsection{Data evaluation of $\mathrm{p} K_{\mathrm{a}}$}

The SOLVER program was used to estimate the $t_{R}$ values of the compounds at each ACN concentration studied and to calculate ${ }_{s}^{s} p K_{a}$ values. For this, the differences between the experimental and theoretically calculated $t_{R}$ values were taken and the sum of the differences was minimized [40]. Besides, the non-linear regression (NLREG) analysis program [31] was used to calculate the ${ }_{S}^{S} p K_{a}$ values of the compounds, taking into account the activity coefficients $(\gamma) \cdot \gamma$ values were calculated with the Debye-Hückel equation based on the ionic strength in the studied mobile phases [16].

Acknowledgements: Financial support of this project by Süleyman Demirel University through the Institutional Research Fund (Project 4826-D2-16) is gratefully acknowledged. We acknowledge Dr. Jose Luis Beltran (University of Barcelona) for kindly providing the NLREG 4.0 program.

Author contributions: Concept - I.D.N., E.C.D.; Design - I.D.N., E.C.D.; Supervision - E.C.D.; Resources - I.D.N., E.C.D.; Materials - I.D.N.; Data Collection and/or Processing - I.D.N., E.C.D.; Analysis and/or Interpretation - I.D.N.; Literature Search - I.D.N., E.C.D.; Writing - E.C.D.; Critical Reviews - I.D.N., E.C.D.

Conflict of interest statement: The authors declared no conflict of interest 


\section{REFERENCES}

[1] Goodman LS, Gilman A, Brunton LL, Goodman \& Gilman's Manual of Pharmacology and Therapeutics, McGrawHill Medical, New York 2008.

[2] Lemke TL, Williams DA, Foye's Principles of Medicinal Chemistry, sixth ed., Lippincott Williams\&Wilkins, USA 2008 .

[3] Barbosa J, Fonrodona G, Marquks I, Sanz-Nebot V, Toro I, Solvent effects on protonation equilibria of peptides and quinolones by factor analysis applied to the correlation between dissociation constants and solvatochromic parameters in acetonitrile-water mixtures. Anal Chim Acta. 1997; 351: 397-405. [CrossRef]

[4] Demiralay EC, Koc D, Daldal YD, Cakır C, Determination of chromatographic and spectrophotometric dissociation constants of some beta lactam antibiotics. J Pharm Biomed Anal. 2012; 71: 139-143. [CrossRef]

[5] Talay A, Demiralay EC, Daldal YD, Ustün Z. Investigation of thermodynamic acidity constants of some statins with RPLC method. J Mol Liq. 2015; 208: 286-290. [CrossRef]

[6] Gumustas M, Sanlı S, Sanlı N, Ozkan SA. Determination of $\mathrm{pK}(\mathrm{a})$ values of some antihypertensive drugs by liquid chromatography and simultaneous assay of lercanidipine and enalapril in their binary mixtures. Talanta. 2010; 82: 1528-1537. [CrossRef]

[7] Li J, Cai B. Evaluation of the retention dependence on the physicochemical properties of solutes in reversed-phase liquid chromatographic linear gradient elution based on linear solvation energy relationships. J Chromatogr A. 2001; 905: 35-46. [CrossRef]

[8] Li J. Prediction of internal standards in reversed-phase liquid chromatography III. Evaluation of an alternativesolvation parameter model to correlate and predict the retention of ionizable compounds. J Chromatogr A. 2002; 982: 209-223. [CrossRef]

[9] Espinosa S, Bosch E, and Rosés M. Retention of Ionizable Compounds on HPLC. 12.The Properties of Liquid Chromatography Buffers in Acetonitrile-Water Mobile Phases That Influence HPLC Retention. Anal Chem. 2002; 74: 3809-3818. [CrossRef]

[10] Avdeef A. Physicochemical Profiling (Solubility, Permeability and Charge State). Curr Top Med Chem. 2001; 1: 277351. [CrossRef]

[11] Manallack DT. The pKa Distribution of Drugs: Application to Drug Discovery. Persp Med Chem. 2007; 1: 25-38. [CrossRef]

[12] Kerns EH, Di L. Physicochemical profiling: overview of the screens. Drug Discov Today Technol. 2004; 1(4): 343-348. [CrossRef]

[13] Bosch E, Rived F, Rosés M. Linear solvation energy relationships between electrolyte pK values and solvent properties for several 2-methylpropan-2-ol-cosolvent mixtures. J Phys Org Chem. 1994; 7: 696-704. [CrossRef]

[14] Bosch E, Rosés M, Herodes K, Koppel I, Leito I , Koppel I, Taal V. Solute-solvent and solvent-solvent interactions in binary solvent mixtures. 2. Effect of temperature on the ET(30) polarity parameter of dipolar hydrogen bond acceptor-hydrogen bond donor mixtures. J Phys Org Chem. 1996; 9(6): 403-410. [CrossRef]

[15] Schoenmakers PJ, Molle S, Hayes CMG, Uunk LGM. Effects of pH in reversed-phase liquid chromatography. AnalChim Acta. 1991; 250: 1-19. [CrossRef]

[16] Barbosa J, Sanz-Nebot V. Standard $\mathrm{pH}$ values in non-aqueous mobile phases used in reversed-phase liquid chromatography. Anal Chim Acta. 1993; 283: 320-325. [CrossRef]

[17] Barbosa J, Buti S, Sanz-Nebot V. Standard pH values for standardization of potentiometric sensors in $10 \%$ (w/w) acetonitrile-water mixtures. Talanta 1994; 41(5): 825-831. [CrossRef]

[18] Bergés R, Sanz-Nebot V, Barbosa J. Modelling retention in liquid chromatography as a function of solvent composition and $\mathrm{pH}$ of the mobile phase. J Chromatogr A. 2000; 869(1-2): 27-39. [CrossRef]

[19] Manderscheid M, Eichinger T. Determination of pKa Values by Liquid Chromatography. J Chromatogr Sci. 2003; 41(6): 323-326. [CrossRef]

[20] Barbato F, La Rotonda MI, Quaglia F. Chromatographic Indexes on Immobilized Artificial Membranes for Local Anesthetics: Relationships with Activity Data on Closed Sodium Channels. Pharm Res. 1997; 14: 1699-1705. [CrossRef]

[21] Drugbank. Open data drug and drug target database [online]. Website http://www.drugbank.ca/drugs/DB00665 (accessed 1 April 2018).

[22] Chemicalize. Website http://www.chemicalize.org. (accessed 18 December 2018). 
[23] Newton DW, Murray WJ, Lovell MW. pKa Determination of Benzhydrylpiperazine Antihistamines in Aqueous and Aqueous Methanol Solutions. J Pharm Sci. 1982; 71(12): 1363-1366. [CrossRef]

[24] Yilmaz Ortak H, Cubuk Demiralay E. Effect of temperature on the retention of Janus kinase 3 inhibitor in different mobile phase compositions using reversed-phase liquid chromatography. J Pharm Biomed Anal. 2019; 164: 706-712. [CrossRef]

[25] Baeza-Baeza JJ, Garc1 $\square$ a-Alvarez-Coque MC. Some observations on the prediction of retention in reversed-phase liquid chromatography using the $\mathrm{pH}$ as main factor. Anal Chim Acta. 2004; 521(1): 61-68. [CrossRef]

[26] Poturcu K, Çubuk Demiralay E. Determination of Some Physicochemical Properties of Mebendazole with RPLC Method. J Chem Eng Data. 2019; 64(6): 2736-2741. [CrossRef]

[27] Barbosa J, Toro I, Sanz-Nebot V. Acid-base behaviour of tripeptides in solvents used in liquid chromatography. Correlation between $\mathrm{pK}$ values and solvatochromic parameters of acetonitrile-water mixtures. Anal Chim Acta. 1997; 347(3): 295-304. [CrossRef]

[28] McCalley DV. Effect of temperature and flow-rate on analysis of basic compounds in high-performance liquid chromatography using a reversed-phase column. J Chromatogr A. 2000; 902: 311-321. [CrossRef]

[29] Buckenmaier SM, McCalley DV, Euerby MR. Overloading study of bases using polymeric RP-HPLC columns as an aid to rationalization of overloading on silica-ODS phases. Anal Chem. 2002; 74: 4672-4681. [CrossRef]

[30] Daldal YD, Demiralay EC, Ozkan SA. Effect of Organic Solvent Composition on Dissociation Constants of SomeReversible Acetylcholinesterase Inhibitors. J Braz Chem Soc. 2016; 27(3): 493-499. [CrossRef]

[31] NLREG Version 4.0. P.H. Sherrod. Website http://www.sandh.com/Sherrod.1991 (Accessed December 15, 2018).

[32] Lacivita E, Leopoldo M, De Giorgio P, Berardi F, Perrone R. Determination of 1-aryl-4-propylpiperazine pKa values: The substituent on aryl modulates basicity. Bioorg Med Chem. 2009; 17: 1339-1344. [CrossRef]

[33] Khalili F, Henni A., East ALL. pKa values of some piperazine at 298, 303, 313 and 323 K. J Chem Eng Data. 2009; 54: 2914-2917. [CrossRef]

[34] Hetzer HB, Robinson RA, Bates RG. Dissociation constants of piperazinium ion and related thermodynamic quantities from 0 to $50^{\circ}$. J Phys Chem. 1968; 72: 2081-2086. [CrossRef]

[35] Barbosa J, Barrón D, Bergés R, Buti S, Sanz-Nebot V. Evaluation of the effect of organic modifier on pK values of diuretics in mobile phases used in LC. Int J Pharm. 1998; 160: 173-185. [CrossRef]

[36] Arayne MS, Sultana N, Siddiqui FA. Simultaneous Determination of Pyridoxine, Meclizine and Buclizine in DosageFormulations and Human Serum by RP-LC. Chromatographia 2008; 67(11/12): 941-945. [CrossRef]

[37] Sher N, Siddiqui FA, Hasan N, Shafi N, Zubair A, Mirza AZ. Simultaneous determination of antihistamine antiallergic drugs, cetirizine, domperidone, chlorphenamine maleate, loratadine, meclizine and buclizine in pharmaceutical formulations, human serum and pharmacokinetics application. Anal Methods 2014; 6: $2704-2714$. [CrossRef]

[38] Tallarida RJ, Murray RB. Henderson-Hasselbalch Equation, in: R.J. Tallarida, R.B. Murray (Ed.), Manual of Pharmacologic Calculations, Springer, New York, 1987, pp.74-75.

[39] Mussini T, Covington AK, Longhi P and Rondinini S. Criteria for standardization of $\mathrm{pH}$ measurements in organic solvents and water + organic solvent mixtures of moderate to high permittivities. Pure Appl Chem. 1985; 57(6): 865876. [CrossRef]

[40] Jozanović M, Sakač N, Jakobović D, Bosnar MS. Analytical characterization and quantification of histidine dipeptides, carnosine and anserine by modeling of potentiometric titration data. Int J Electrochem Sci. 2015; 10: 5787-5799.

This is an open access article which is publicly available on our journal's website under Institutional Repository at http://dspace.marmara.edu.tr. 